\title{
How do I make science journal
}

\author{
Min Suk Chung
}

Department of Anatomy, Ajou University School of Medicine, Suwon, Korea

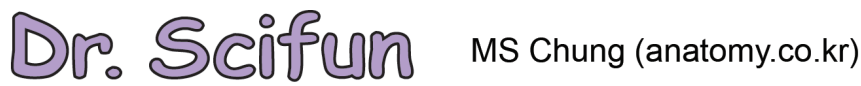

Episode 1: How do I make SCI journal?
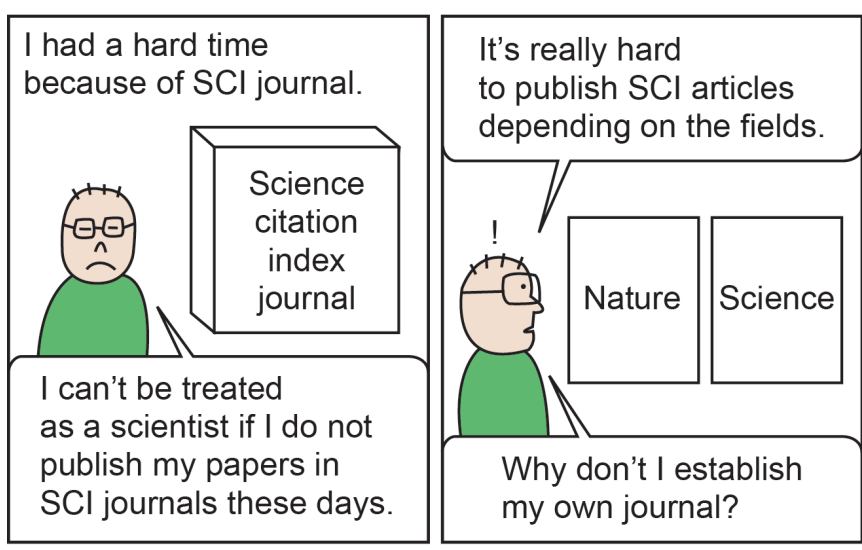

Received: February 13, 2015 Accepted: February 14, 2015

Correspondence to Min Suk Chung dissect@ajou.ac.kr

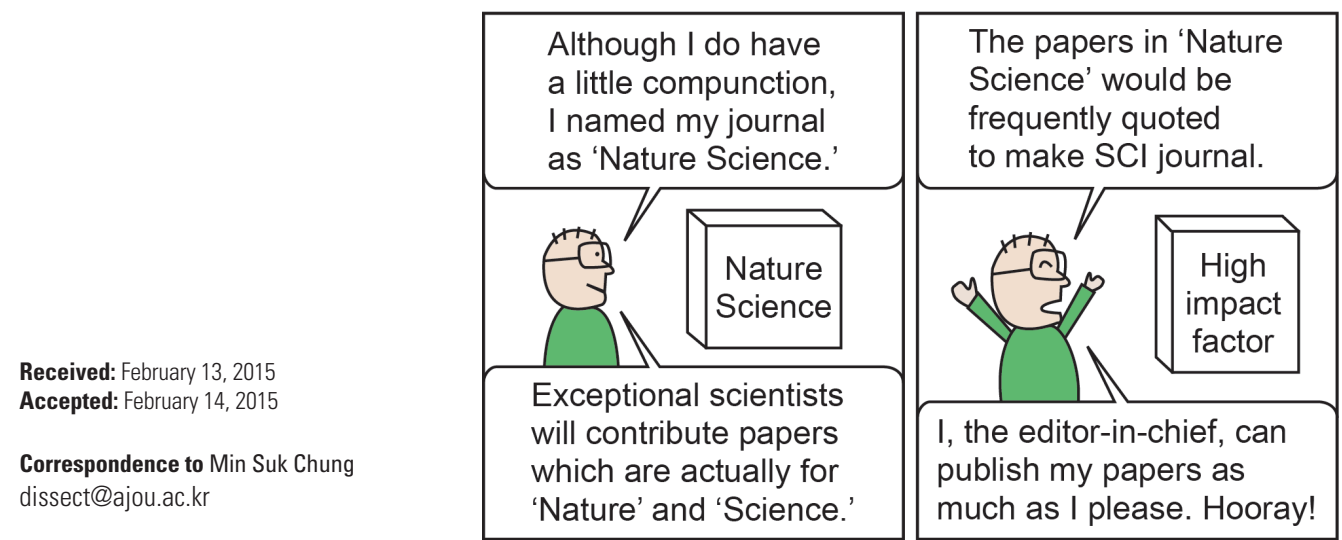

ORCID

Min Suk Chung

http://orcid.org/0000-0002-0527-9763
This is an open access article distributed under the terms of the Creative Commons Attribution Non-Commercial License (http://creativecommons.org/ licenses/by-nc/3.0/), which permits unrestricted use, distribution, and reproduction in any medium, provided the original work is properly cited. 


\section{(D)}

Episode 6: Science and nature
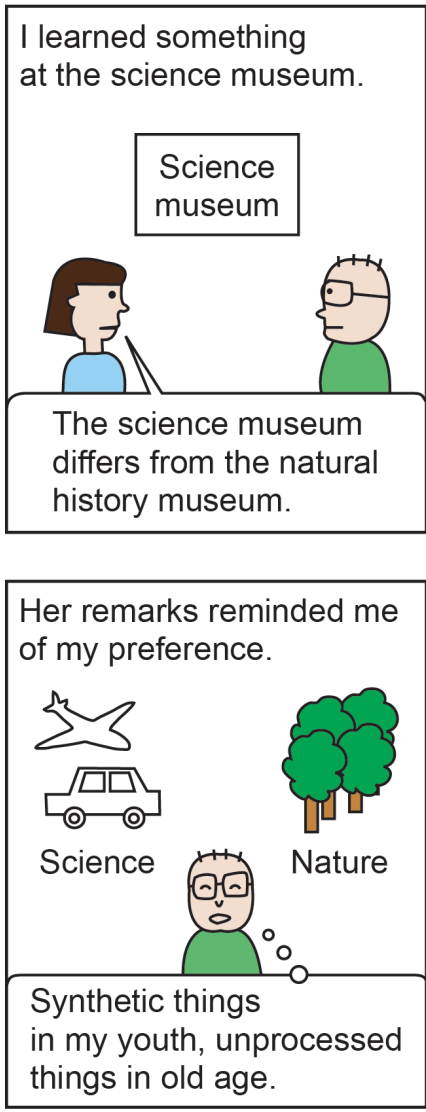

The science museum exhibits man-made things such as machines,

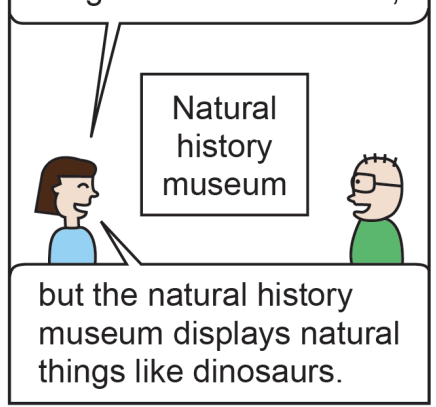

I also thought of journals called Science and Nature.

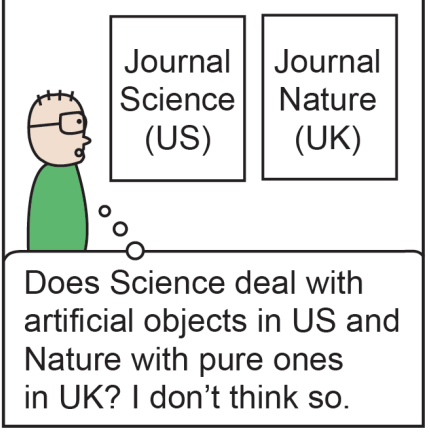

'Scientific' has stricter meaning than 'natural.' So scientists seem to have to be 'scientific' rather than 'natural.' But a veteran scientist is not only 'scientific' but also 'natural.' Two words are thought to be closely related with each other. Science is nature.

\section{Dr. Scifonen}

MS Chung (anatomy.co.kr)

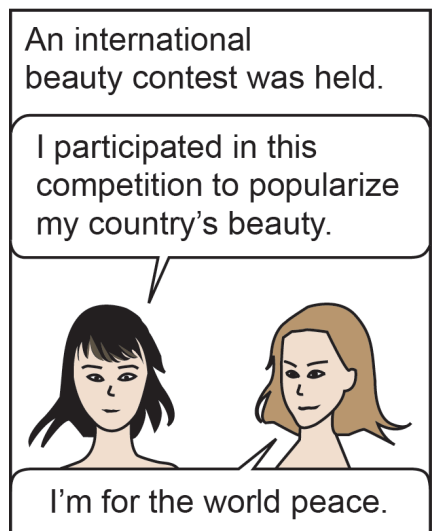

I'm for the world peace.

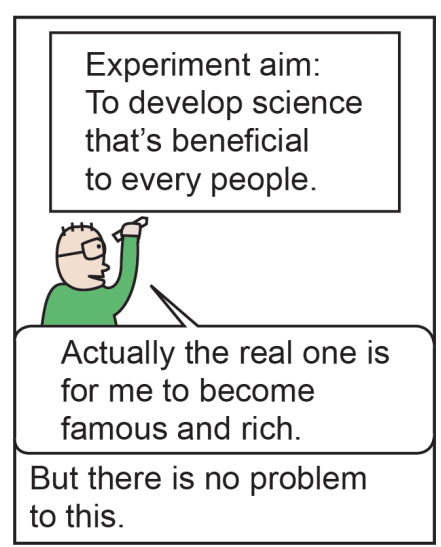

There is something called 'invisible hand' in capitalism. Executives, employees and customers only care about their own interests. But these selfish deeds are also altruistic since it can be helpful to other's benefits. Invisible hands turning selfishness into altruism exists in a beauty contest and science. 
Episode 21: Pleasure of drawing comics
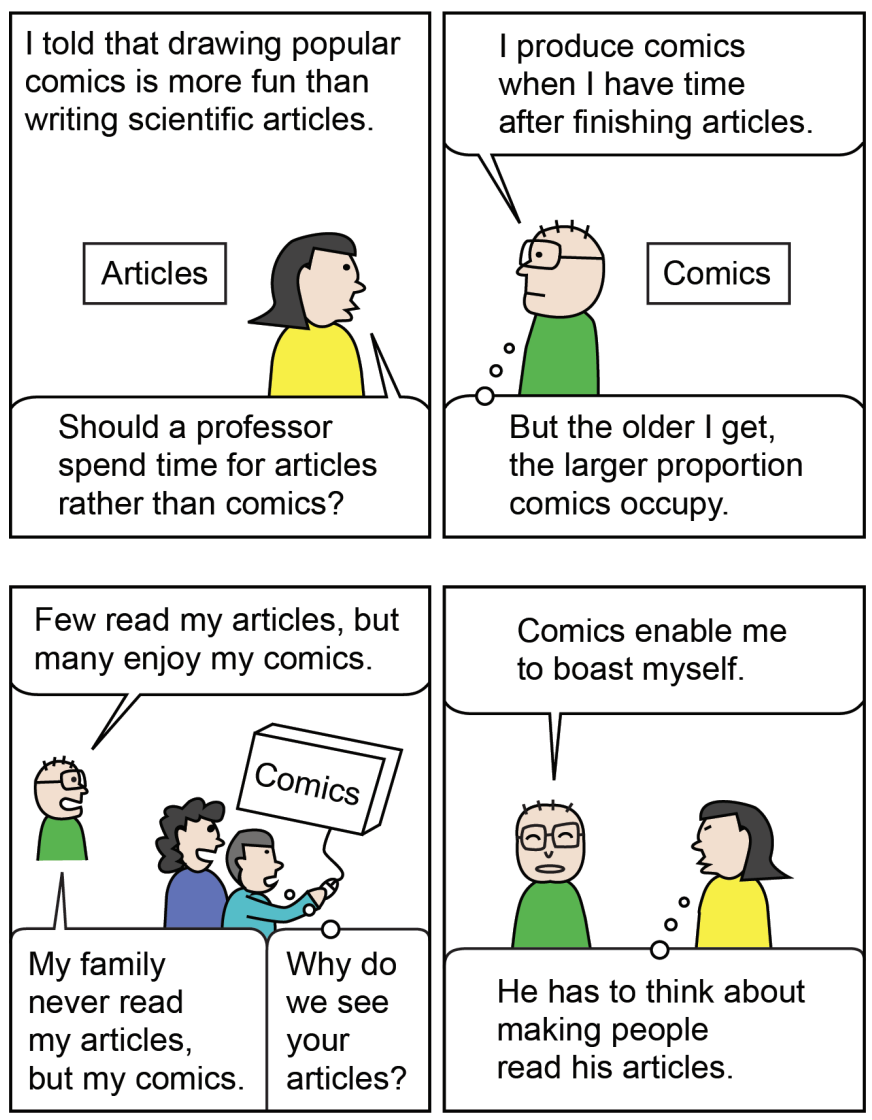

Actually there are very few people to read scientific articles. Suppose that the impact factor of a journal is 1. It means only one person to peruse an article in the journal. On the contrary, abundant persons enjoy comics regardless of their specialty. Hopefully, like me, more scientists will challenge the comics regarding to their scientific activities.

Editor's comments: The science cartoons by Dr. Min Suk Chung will be published in Science Editing from this issue. Dr. Chung, anatomist, has been famous not only for his work on Visible Korean project but also on science cartoons. The cartoons are generously provided by Dr. Chung, which are available from: http://anatomy.co.kr/. 